\title{
Applicability of PV Rooftops Versus Agriculture Rooftops in the Residential Buildings of Nasr City, Cairo
}

Mai A. Marzouk ${ }^{1,2}$ *, Mohamed A. Salheen ${ }^{2}$ and Ahmed A. Faggal ${ }^{1}$

1 Ain Shams University, Faculty of Engineering, Department of Architecture, 11566, Egypt

2 Ain Shams University, IUSD Program, 11566, Egypt

* Correspondence: mai adel 28@eng.asu.edu.eg

Citation: Marzouk, M. A.; Salheen, M. A.; Faggal, A., 2022, Applicability of PV Rooftops Versus Agricultural Rooftops in the Residential Buildings of Nasr City, Cairo. SUPTM 2022 conference proceedings sciforum-053134. https://doi.org/10.31428/10317/10592

Publisher's Note: UPCT and Sciforum stays neutral with regard to jurisdictional claims in published maps and institutional affiliations.

Copyright: (c) 2022 by the authors. Submitted for possible open access publication under the terms and conditions of the Creative Commons Attribution (CC BY) license (https://creativecommons.org/license s/by/4.0/).
Abstract: Urban rooftops in the Egyptian built environment are a clear example of a massively wasted resource. They can contribute to energy and food production as well as increase the return on investment in the real estate sector by implementing Agri and PV rooftop systems. The paper aims at tapping into the unexplored case of multi-unit residential buildings of Cairo to assess the Agri and PV systems' applicability on their rooftops. For this purpose, it conducts a spatial analysis for one of the Cairene middle-income districts; Nasr city. Overlaying multiple layers of applicability aspects derives a conclusion about the percentage of applicable rooftops for Agri versus PV systems in the district's different blocks typologies.

Keywords: Rooftop Agriculture; Urban Agriculture; Solar Rooftops; Green Buildings; Rooftop Architecture

\section{Introduction}

Agri and PV rooftop systems can provide multiple benefits that help reduce the excessive use of resources in Egypt while making use of urban rooftops as an overlooked resource. Food insecurity and malnutrition levels are increasing annually as a result of the increasing food prices and diminishing agricultural land in favor of urban expansion [1,2]. Agri-rooftops are a promising urban agriculture method that can secure local food production and healthy food provision for different segments of the society $[3,6]$.

Rapid population growth, massive urbanization trends, and extensive heat waves are leading to increasing electricity demands $[4,5]$. Energy sources' diversification and the support of on-site generation by PV rooftops are key strategies for facing this demand [6].

The residential land use makes up $64 \%$ of all land uses in Cairo [1,7], thus its rooftops represent a huge under-utilized area. It is suitable for Agri-rooftops where the unit owners can easily follow up on the systems and benefit from the high-quality produce. It is also the highest consuming sector of electricity, consuming around $50 \%$ of the low and medium voltages $[5,8]$. Thus, it possesses a huge potential for hosting both systems.

The selection of the middle-income segment as a target group of the conducted analysis is accounted for being the most untapped segment. Almost all Agri and PV rooftops projects in Egypt targeted the heavily subsidized lower-income or the higher-income that have the financial resources [9]. The middle-income fall under the category of "Early adopters" as identified by Rogers in his "Diffusion of Innovation theory" (2003) that defined them as "Opinion leaderships but more attached to the local population in their status and level of innovativeness" [10], therefore it is a segment worth investigating.

The paper aims at exploring the untapped context of the middle-income multi-unit residential buildings and assessing the applicability of Agri and PV systems on its rooftops. It formulates a replicable framework for conducting the applicability analysis of these systems in the Cairene context by overlaying different spatial aspects. In addition, it concludes with the applicability percentage on the rooftops of the selected case study blocks. 


\section{Case Study Description}

Nasr City; one of Cairo's middle-income districts was selected to host the case study blocks. Nasr City was built in the socialist era to host middle-income families in cooperative housing [11]. It has transformed over the years to host a mix of single-family houses and multi-family buildings that reach up to 13 floors in response to the exploding population $[11,12]$. Two blocks in Nasr city were analyzed; block (A) represents the private multi-unit residential blocks, and block (B) represents the cooperative housing blocks.

\section{Methodology}

The paper adopts a case study approach to identify the potentials and constraints of the systems' adoption in this specific context. Site visits to the two blocks were conducted to create a profile that covers all spatial aspects. The study used a combination of manual and GIS-based selection methods for data analysis. The manual selection was used by $[13,14]$ to identify rooftops suitable for Agri systems, and by $[15,16]$ for PV systems. According to [19], this method depends on manual identification of the determinant aspects using maps and on-site images then comparing them to literature-based thresholds concluding with the rooftops' suitability to host the systems. The shading analysis used a GISbased method which was adopted by [3] for Agri-rooftops and by [18,19] for PV rooftops.

\section{Spatial Aspects Thresholds and Applicability Results}

Each of the theoretically and contextually outlined aspects is analyzed for the two blocks.

\subsection{Building Height}

For Cairo, usually building height does not add any load on Agri-rooftops [20] or PV rooftops. Wind load is checked against the load-bearing capacity of both systems only for buildings exceeding 10 floors [21]. Block (A) has 3 to 17 floors, while block (B) has 5 floors. The applicability percentage of Agri-rooftops on Block (A) buildings (> 10 floors) is $80 \%$ due to the needed wind moderation strategies to overcome the loads at this height (4 times the wind load $=280 \mathrm{Kg} / \mathrm{m}^{2}$ ) [21]. For PV rooftops, the load-bearing capacity of the panels is $244 \mathrm{~kg} / \mathrm{m}^{2}$ [23], thus $20 \%$ was also deducted but was compensated by the high sun exposure at this height. Block (B) buildings achieved $100 \%$ applicability ( $<10$ floors).

\subsection{Load Bearing Capacity LBC}

Agri systems add to the live loads around $20-75 \mathrm{~kg} / \mathrm{m} 2$ according to their type [20,22]. While PV systems add to the dead loads (e.g.: crystalline panels add $14-20 \mathrm{~kg} / \mathrm{m} 2$ ) [23,24]. Site visits confirmed that all buildings have concrete skeleton structures and their loadbearing capacity was identified based on the concrete building code. For block (A), rooftop floors withstand a live load of the typical floor $(200-300 \mathrm{~kg} / \mathrm{m} 2)$, while block (B) withstand the live load of a usable last floor $(200 \mathrm{~kg} / \mathrm{m} 2)$ [25]. Loads added by Agri and PV systems are less than the acceptable ranges outlined above, thus their applicability is confirmed.

\subsection{Rooftop Area}

For Agri-rooftops, there is no minimum threshold for the area to cover $[3,20,26]$. The maximum system coverage is $60 \%$ of the total area; i.e. Roof Cover Ratio (RCR) is 0.6 for maneuvering $[13,14]$. For PV rooftops, the minimum area for having an efficient system is $50 \mathrm{~m}^{2}$ for residential uses ( $5 \mathrm{kWp} / \mathrm{month}$ ) [24]. The RCR, in this case, is between 0.6 to 0.9 leaving room for the panels' spacing [23,27]. Block (A) and (B) have areas of $335 \mathrm{~m} 2$ and $760 \mathrm{~m}^{2}$. After applying the Roof Cover Ratio (RCR) for both systems, the remaining available areas are more than the minimum, so the applicability percentage is $100 \%$ for all.

\subsection{Obstructions and Materials}

The obstructions include clutter and competing functions existing on the roof such as poultry rearing, livestock or dogs raising, and Satellite dishes $[23,28]$. Finishing materials vary in Cairo where the most important is the waterproofing membrane [23]. 
For both blocks, the rooftops were finished with tiles and waterproofing membranes. The obstructions were classified based on their level to slightly obstructed (obstructed area $\leq 40 \%$ of roof area) having $100 \%$ applicability, moderately obstructed (obstructed area $=40 \%$ to $70 \%$ ) having $90 \%$ and $70 \%$ applicability for Agri and PV systems respectively, or highly obstructed (the obstructed area $\geq 70 \%$ ) having $70 \%$ and $50 \%$ respectively. Block (A) rooftops had more structural obstructions than block (B) due to the elevator and stairs rooms. Satellite dishes and clutter were the most common functions on both blocks.

\subsection{Rooftop Accessibility and Safety}

The easiness and safety of accessibility are more critical to Agri-rooftops to ensure the farmers' access and transporting of materials and equipment [29]. For PV rooftops, accessibility is mainly needed for system mounting and occasional panels' cleaning. Accessibility was classified into three categories: easy accessibility through elevator/stairs having $100 \%$ applicability for both systems. Medium accessibility bound to caretaker approval and having 90\% for both systems. Difficult accessibility through a vertical stair having $0 \%$ and $90 \%$ for Agri and PV systems respectively. $75 \%$ of block (A) buildings have easy accessibility, while $89 \%$ of block (B) are difficult to access due to vertical stairs.

\subsection{Utilities Provision on the Rooftop}

The identified utilities include water access, drainage point, and electricity access. Water access is necessary to water plants [29], and to clean the PV panels [27]. With water usage, a drainage point is needed to avoid any leakage risks [28]. Electricity is needed to power Agri systems components. $80 \%$ of block (A) buildings have a full provision of the three utilities, while $94 \%$ of block (B) buildings have no access to any of them. Utilities' provision is of extreme significance to Agri-rooftop thus the roofs with no access were discarded and those with one utility get 30\% applicability but get $70 \%$ for PV systems.

\subsection{Shadow Analysis}

Shadow impact on both systems is very critical, so a shadow analysis was conducted on 4 days (in the 4 seasons) at 3 times (9 AM, 12 PM, 3 PM) using Google SketchUp shadow tools. Shadow levels were categorized into slightly shaded (shaded area $\leq 40 \%$ of rooftop area) having $100 \%$ applicability for both systems, moderately shaded (shaded area $=40 \%$ to $70 \%$ ) having $80 \%$ and $60 \%$ for Agri and PV systems respectively, and highly shaded (shaded area $\geq 70 \%$ ) having 60\% and $0 \%$ for the Agri and PV systems. Block (B) buildings have $100 \%$ applicability for both systems since no shadows exist due to equal heights.

\section{Conclusion}

By overlapping these results and percentages, a conclusion about the applicability potential of Agri and PV rooftops can be reached as shown in Figure 1. PV rooftops are more applicable in both blocks where it is applicable on $85 \%$ of block (A) and $100 \%$ of block (B). While Agri-rooftops are applicable on 75\% and 10\% of block (A) and (B) respectively. The main barriers facing the Agri systems were the lack of accessibility, followed by the lack of utilities' provision and the negative impact of casted shadows. Shadows were also the main barrier facing PV systems. The replicability potential of block (A) typology is very high in Nasr City. Thus, the generalization of this block's results is possible. For block (B), the generalization potential is limited since some characteristics are specific to this type of cooperative housing. However, this particular block was not the target, but identifying the unfavorable block conditions is the added value of the conducted analysis.

Acknowledgments: This research was based on an M.Sc. Thesis titled 'Rooftops from Wasted to Scarce Resource; The Competition between Harvesting Crops and Solar Energy in Nasr City" in IUSD double degree Master's program between Ain Shams University in Egypt and the University of Stuttgart in Germany, funded by the DAAD. Assistance provided by the thesis advisor Mr. Zakaria Yahia El Sayed, the researcher at CLAC, is highly appreciated.

Conflicts of Interest: The authors declare no conflict of interest. 

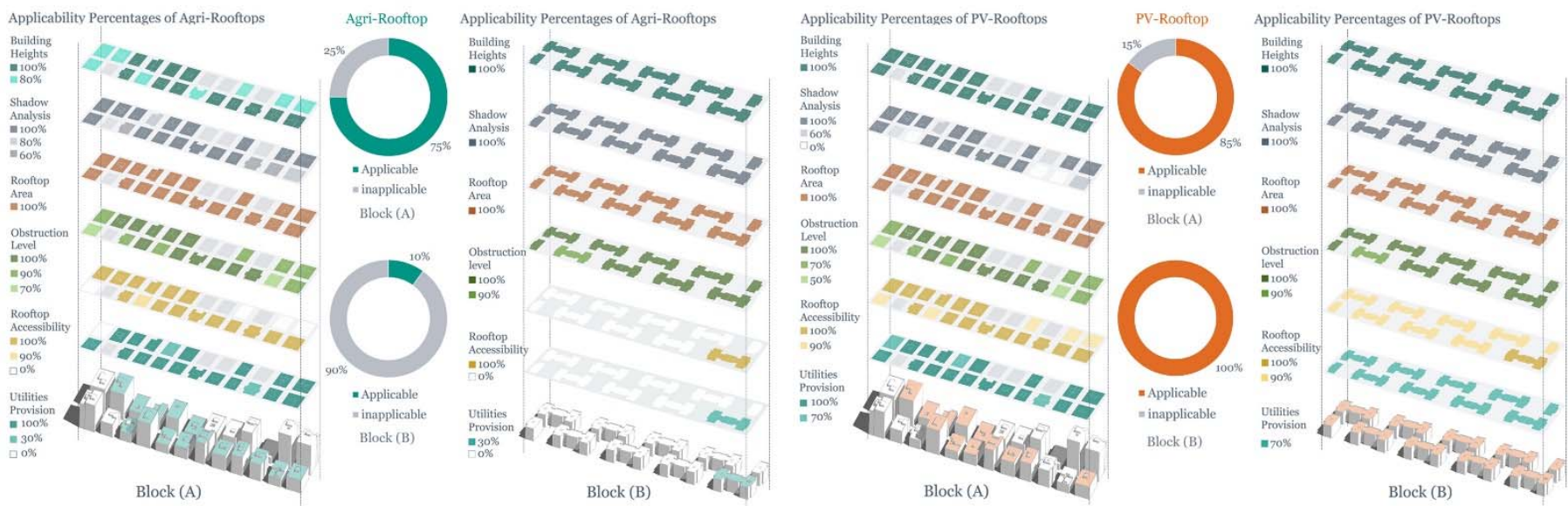

Figure 1. Agri-rooftop and PV rooftop Applicability Results for Block (A) and (B). Source: Author

\section{References}

1. Megahed, Y., Cabral, P., Silva, J. and Caetano, M. Land Cover Mapping Analysis and Urban Growth Modelling Using Remote Sensing Techniques in Greater Cairo Region-Egypt. ISPRS International Journal of Geo-Information 2015, (ISSN 2220-9964).

2. WFP. Egypt I World Food Programme, 2021. https://www.wfp.org/countries/egypt (Accessed 1 Dec. 2021).

3. Berger, D. A GIS Suitability Analysis of the Potential for Rooftop Agriculture in New York City. Master's Degree, Columbia University, Columbia, 2013.

4. Hanna, G. Green Energy and Green Buildings in Egypt. International Journal of Engineering Research and Applications 2013, 3(4).

5. EEHC. Annual Report of the Egyptian Electricity Holding Company 2019/2020. EEHC: Cairo, Egypt, 2020.

6. Tablada, A., Kosoric, V., Lau, S. K., Yuan, C., \& Lau, S. Productive facade systems for energy and food harvesting: A prototype optimisation framework. Proceedings of 33rd PLEA International Conference: Design to Thrive, PLEA 2017, 3(July), 3595-3602.

7. CAPMAS. Statistical Yearbook for Housing Sector. Central Agency for Public Mobilization and Statistics: Cairo, Egypt, 2020.

8. Elrefaei, H.H., \& Khalifa, M.A. A Critical Review on the National Energy Efficiency Action Plan of Egypt. Journal of Natural Resources and Development 2014, 4. Pp.18-24. DOI:10.5027/jnrd.v4i0.03.

9. Marzouk, M. Harvesting Crops versus Solar Energy on Cairo's Residential Rooftops - Status-Quo Analysis. Trialog Journal 2018, 2/2017 (0724-6234), pp.32-42.

10. Rogers, E. Diffusion of Innovations, 5th ed.; Free Press: New York, US, 2003.

11. Shaheen, S. Nasr city project, the middle income city. Walycenter journal 2013.

12. Frochaux, M. and Martin, A. (2010). Nasr city. ETH Studio Basel Contemporary City Institute 2010, Draft Ed.

13. M. Reese, N. An Assessment of the Potential for Urban Rooftop Agriculture in West Oakland, California. Master's Degree, University of San Francisco, 2014.

14. Bay Localize. Tapping the Potential of Urban Rooftops; Rooftop Resources Neighborhood Assessment, 2007. pp.1-13.

15. Johnson, G.; Armanino, D. Solar 2004 Conference: GIS Tools for Community Development Applications, San Rafael, 2004.

16. Ordonez, J.; Jadraque, E.; Alegre, J.; Martinez, G. Analysis of the Photovoltaic Solar Energy Capacity of Residential Rooftops in Andalusia (Spain). Renewable and Sustainable Energy Reviews 2010, (14); pp. 2122-2130.

17. Melius, J., Margolis, R. and Ong, S. Estimating Rooftop Suitability for PV: A Review of Methods, Patents, and Validation Techniques. Technical Report NREL/TP6A20-60593, National Renewable Energy Laboratory (NREL) 2013, pp.6,9.

18. Jo, J.H.; Otanicar, T.P. A Hierarchical Methodology for the Mesoscale Assessment of Building Integrated Roof Solar Energy Systems. Renewable Energy 2011, (36), pp. 2992-3000.

19. Anders, S.; Bialek, T. Technical Potential for Rooftop Photovoltaics in the San Diego Region. Energy Policy Initiatives Center University of San Diego School of Law and San Diego Gas E Electric.

20. El Sayed, Z. Interview with the Researcher at CLAC. Personal Communication, 2016.

21. El-Reedy, M. Advanced Materials and Techniques for Reinforced Concrete Structures, 2nd ed. CRC Press, 2015.

22. St. Lawrence, J. Urban Agriculture:The Potential of Rooftop Gardening. City Farmer,Canada's Office of Urban Agriculture,1996.

23. ADB (Asian Development Bank). Handbook for Rooftop Solar Development in Asia. Mandaluyong City, Philippines, 2014.

24. Nauman, A., Yassin, M. Interview with the team in Solariz Egypt company. Personal Communication, 2016.

25. MHUU (Ministry of Housing, Utilities and Urban Development). The Egyptian code for calculation of loads and forces in structural and building works. HBRC: Cairo, Egypt, 2008, chapter 4.

26. Abul Fotouh, H. Interview with the CEO of Al Bustani company. Personal Communication, 2016.

27. Tawfik, H. Interview with Head of Commercial Operations in Cairo solar company. Personal Communication, 2016.

28. Brainard, S. Rooftop Garden Construction, presentation in RISE institute, AUC Cairo, 2015.

29. Kortright, R. Evaluating the Potential of Green Roof Agriculture. Trent University. City Farmer, Canada's Office of Urban Agriculture, 2001. Available at: http://www.cityfarmer.org/greenpotential.html (Accessed 15 May 2021). 